\title{
A Process Model of Entrepreneurial Alertness Among Technopreneurs
}

\author{
Zohreh Hassannezhad ${ }^{1}$, Mohammad Reza Zali ${ }^{1}$, Nezameddin Faghih ${ }^{1}$, Reza Hejazi ${ }^{1} \&$ Ali Mobini ${ }^{1}$ \\ ${ }^{1}$ Faculty of Entrepreneurship, University of Tehran, Tehran, Iran \\ Correspondence: Mohammad Reza Zali, Faculty of Entrepreneurship, University of Tehran, Tehran, Iran.
}

Received: December 30, 2019

Accepted: January 24, 2020

Online Published: February 12, 2020

doi:10.5539/ibr.v13n3p96

URL: https://doi.org/10.5539/ibr.v13n3p96

\begin{abstract}
Alertness is a foundational concept in current understandings of the spotting and exploitation of entrepreneurial opportunities. In this paper its two broad aspects from psychology have been explored and a model has been generated; reflecting the hierarchical relation between alertness aspects and mindfulness factors. Results show that mindfulness mediates the relationship between alertness and novelty creation. We use Interpretive Structure Modeling (ISM) to create the model of entrepreneurial alertness and mindfulness. The model is generated on the basis of ten technological entrepreneurs in the ISM session in Iran. They voted on the mutual relations of the elements. The results showed that mindfulness fosters alertness, which then leads to the creation of novel things. This also shows that mindfulness deserves more investigation for its potential role in other parts of entrepreneurial process.
\end{abstract}

Keywords: mindfulness, entrepreneurial alertness, technological entrepreneurship, ISM

\section{Introduction}

Entrepreneurial alertness (EA) is the most important cognitive capability of entrepreneurs in spotting and exploiting entrepreneurial opportunities (Baron, 2004, 2006; Tang, Kacmar \& Busenitz, 2012; Valliere, 2013). Yet, despite the importance of it, there is not a clear theory about how entrepreneurial alertness is created and developed in entrepreneurs. Kirzner, as the first developer of the theory, didn't reveal it and declared "my own work has nothing to say about the secrets of successful entrepreneurship" (Kirzner, 2009:145) and he doesn't explain the essence or nature of this entrepreneurial feature (Kirzner, 2009). The theories and the scales presented in recent years to elaborate entrepreneurial alertness do not explain the antecedents of alertness. There are numerous studies that had a focus on antecedents of alertness. But the studies were mainly testing the effect of a single factor on entrepreneurial alertness without a holistic view toward it. Table 1 is a brief summary of the research works that tried to figure out the effects of single factors on alertness.

Moreover, the broader psychological theories of "alertness", which is considered as an aspect of attention that comprises both intrinsic and phasic aspects (Strum \& Willmes, 2001), have somehow been neglected in entrepreneurial context. Intrinsic alertness is considered as a person's endogenous cognitive control over their wakefulness. It is defined as the "internal control of arousal without needing any external cue" (Sturm et al., 1999; Sturm \& Willmes, 2001; Sturm et al., 2004). In contrast, phasic alertness can be considered as increasing readiness in response to exogenous cues (Sturm \& Willmes, 2001). In entrepreneurial context, however, only the phasic aspect of alertness is mentioned and has not fully reflected this original broader conception. Researchers of EA have mostly limited their efforts towards exploring the cognitive roots of the concept. By borrowing a variety of theoretical lenses from cognitive science, such as pattern theory (Baron 2006), schema theory (Gaglio \& Katz 2001; Valliere 2013), regulatory focus theory (Tang 2009), signal detection theory (Baron 2004), and attention theories (Valliere 2013), scholars have started to map out the entrepreneurial implications of phasic alertness. Following the alertness theory of Israel Kirzner (1973), which was a phasic perspective on alertness, scholars started to explore this phasic alertness and its components (Yu 2001; Tang et al. 2012). But the potential implications of intrinsic alertness remain unexplored.

Limited research has been done into approaches for operationalizing and measuring entrepreneurial alertness as well. Despite recent efforts done regarding this issue, still the operationalization of entrepreneurial alertness for empirical measurement is an under-developed area of research. This is likely a result of the ongoing conceptual work still being done to formally define and validate the entrepreneurial alertness construct.

Having a brief review on the entrepreneurial alertness research, we realized that the concept is still vague in 
conceptualization and operationalization, and that a holistic view is somehow neglected in the literature. The aim of this research is to shed light on the concept of alertness that could a) provide an integrated model of alertness reflecting the essential elements and the process of alertness, $b$ ) represent the intrinsic aspect of alertness neglected in the literature, c) provide detailed elements of cognitive approaches towards alertness, and d) provide a linkage between individuals' general alertness in life and alertness to entrepreneurial opportunities. A theoretical lens with the focus on cognitive drivers of alertness is taken into consideration. In order to provide a perspective to be able to represent the intrinsic aspect of alertness, mindfulness theory has been used. Mindfulness is a heightened and deliberate awareness of both the internal and external experiences taking place in the present moment (Kabat-Zinn, 1990). Relying on this theory borrowed from psychology, the aim of this paper is to present a process based model of entrepreneurial alertness. The paper proceeds as follows: First, the theoretical background literature is explored, second the methodology is explained, third the practical definitions of the elements of the model are provided, and finally the model is presented and discussed.

Table 1. Entrepreneurial Alertness Antecedents Research

\begin{tabular}{ll}
\hline \multicolumn{1}{c}{ Citation } & \multicolumn{1}{c}{ Research Focus } \\
\hline $\begin{array}{l}\text { (Ardichvili et } \\
\text { al., 2003) }\end{array}$ & $\begin{array}{l}\text { Theory of the opportunity identification } \\
\text { process. }\end{array}$ \\
(Tang, 2008) & $\begin{array}{l}\text { Examining the effect of environmental } \\
\text { munificence on entrepreneurial alertness. }\end{array}$ \\
(Craig \& & $\begin{array}{l}\text { Investigating the factors affecting } \\
\text { innovativeness and alertness. }\end{array}$ \\
$\begin{array}{l}\text { Johnson, 2006) } \\
\text { 2009) } \\
\text { (Tang et al., } \\
\text { 2009) }\end{array}$ & $\begin{array}{l}\text { Incorporating types of knowledge theory } \\
\text { Developing entrepreneurial alertness both } \\
\text { theoretically and empirically. }\end{array}$
\end{tabular}

(Obschonka et Elements of entrepreneurial mindset al., 2017) among high school students are explored.

(Nikraftar \& Opportunity recognition in tourism-sector Hosseini, 2016) SMEs.

(Ma \& Huang, Strategic orientation, knowledge 2016) acquisition and entrepreneurial alertness of global supplier firms.

(Syed \& Entrepreneurial alertness and

Mueller, 2015) entrepreneurial passion.

(Indrawati et The relationship between environmental al., 2015) dimensions and entrepreneurial commitment with the mediating role of entrepreneurial alertness.

(Schøtt, 2017) Comparison of entrepreneurial intention among immigrant and indigenous youth in Europe.

(Ghasemi \& The effect of market elements on Rowshan, entrepreneurial alertness.

Findings
Alertness is heightened by the coincidence of these three
elements: certain personality traits, relevant prior knowledge,
and social networks.

Environmental munificence has significant influence on alertness of entrepreneurs with greater self-efficacy, which results in higher commitment.

Business training can boost student abilities to find entrepreneurial opportunities.

Two types of local knowledge about social and commercial situations have influence on entrepreneurial alertness.

Social cognition is an antecedent to entrepreneurial alertness in three ways: how entrepreneurs gain new information applying pre-existing knowledge, how they respond to new information clues, and how they filter information.

Personality traits and certain age-appropriate competencies, including leadership, self-esteem, creativity, and proactivity motivation, have significant effect on young adult alertness and intention to become an entrepreneur.

Self-efficacy, social networks, and prior knowledge are the antecedents of entrepreneurial alertness in tourism SMEs.

Technical knowledge and market knowledge acquisition are affected by strategic orientation, boosting entrepreneurial alertness.

Passion increases entrepreneurial alertness indirectly by motivating proactivity, creativity, and a learning goal orientation.

Entrepreneurial alertness is significantly affected by entrepreneurial complexity and self-efficacy.

First and second-generation immigrants tend to have higher self-efficacy and entrepreneurial alertness compared to indigenous youth.

Entrepreneurial alertness is positively affected by market elements such as market disequilibrium, accuracy and timeliness, schema complexity, counterfactual thinking, frame breaking, and sensitivity to profit potential.

\section{Theoretical Framework}

\subsection{Entrepreneurial Alertness Factors}

Our understanding of entrepreneurial alertness has its roots in the objective view toward entrepreneurial opportunities. When Kirzner defines entrepreneurial alertness as "the ability to notice without search opportunities that have hitherto been overlooked" (Kirzner, 1979), he implies that opportunities objectively exist in the outer world and that the reason they have been overlooked lies in a lack of alertness on the part of the entrepreneurs; entrepreneurs must prime themselves to stay alert in order to detect any opportunities that surround them. Following on this, the majority of EA scholars have since worked from this same assumption as the foundation for their theorizing, and have investigated the factors that might boost the phasic alertness of entrepreneurs for detecting external opportunities. But relying solely on this view runs counter to more recent thinking associated 
with the creativity view of the nature of entrepreneurial opportunities, a view in which opportunities are endogenously created through purely abductive processes (Sarasvathy, Dew, Velamuri \& Venkataraman, 2003; Alvarez \& Barney 2007). Opportunities do not always exist independent of entrepreneurs. Rather, "they are created, endogenously, by the actions, reactions, and enactment of entrepreneurs exploring ways to produce new products or services" (Alvarez \& Barney 2007). The essence of EA in this subjective perspective is comparable to the intrinsic alertness concept in cognitive psychology. From this perspective, there is no external cue to be apprehended and reacted to. Rather, entrepreneurs have executive control over their internal cognitive mechanisms and, by exercising them deliberately, can enhance their intrinsic EA and become able to create novel opportunities from pre-existing objective conditions. However, it may not be easy for individuals to have good control over their internal cognitive mechanisms and their emotional or sensory systems. In fact, it is considered to be one of the most important issues in current psychological studies. In entrepreneurial context, there are two major theories that had a focus on the factors of alertness. Tang et al. (2012) developed a scale for measuring entrepreneurial alertness, which implied a theoretical construct. Alertness is a process of "scanning and search" for new information, "association and connection" of the information with opportunities and finally "evaluation and judgement" of the founded opportunities. In this approach, alertness is a series of deliberately done activities leading to an entrepreneurial opportunity. A year later, Valliere (2013) focused on the cognitive nature of alertness and tried to differentiate cognition from action. He explained that alertness is a result of some schematic features in mind which are "schematic richness", "schematic association" and "schematic priming"

In our comprehensive exploratory model of alertness, we included the factors related to both of the above-mentioned approaches. Table 2 provides the alertness factors with their operational definitions.

Table 2. Alertness Factors and Operational Definitions

\begin{tabular}{ll}
\hline \multicolumn{1}{c}{ Factor } & \multicolumn{1}{c}{ Operational Definition } \\
\hline $\begin{array}{l}\text { Schematic richness } \\
\text { (Valliere, 2013) }\end{array}$ & $\begin{array}{l}\text { Schematic richness is built upon prior knowledge, experiences and } \\
\text { education. }\end{array}$ \\
\hline Attention to under-utilized resources (Valliere, 2013) & $\begin{array}{l}\text { Individuals who have a rich schema about under-utilized resources } \\
\text { can find and exploit these resources to meet the needs or do } \\
\text { innovations. }\end{array}$ \\
$\begin{array}{l}\text { Thinking deeply about the strengths and weaknesses } \\
\text { of a system (Valliere, 2013) }\end{array}$ & $\begin{array}{l}\text { People who have a rich cognitive model of entrepreneurship look for } \\
\text { the entrepreneurial aspects of the system in whatever system they are } \\
\text { in. }\end{array}$
\end{tabular}

Utilizing existing technology for new products Individuals with a rich entrepreneurial consciousness pattern identify (Valliere, 2013) the entrepreneurial aspects of existing facilities and technologies and exploit them to produce new products.

Schematic Association $\quad$ Schematic association is strengthened by entrepreneurial practice.

(Valliere, 2013) The more you practice, the better you can associate unrelated things together.

Sensitivity to entrepreneurial opportunities (Valliere, Individuals with schematic association are sensitive to entrepreneurial 2013)

Opportunity spotting “antenna” (Valliere, 2013) opportunities and can find the opportunities without intentional tries. People who are accustomed to connecting different subjects to one another will unconsciously find the ability that some thinkers act as an antenna in their minds, and they will be able to identify opportunities without conscious search and only with the cognitive processes that occur.

Schematic priming (Valliere, 2013) This cognitive paradigm is directly related to the extent to which one is motivated to identify opportunities. As much as identifying opportunities for the individual is a priority, one will be consciously searching for entrepreneurial opportunities.

Deliberate search for opportunities (Valliere, 2013) Those who consider identifying entrepreneurial opportunities as one of their top priorities and intend to start a business are consciously and deliberately seeking opportunities.

Thinking about the "next big thing" (Valliere, 2013) These people always think about doing a great job in their minds, and that is what motivates them to identify entrepreneurial opportunities.

Scanning and search

(Tang et al., 2012) Searching for information is an activity undertaken by individuals to identify entrepreneurial opportunities. Activities such as studying, searching the Internet, acquiring information, etc. are conscious efforts to identify entrepreneurial opportunities.

Active search for information (Tang et al., 2012) People who are aware of entrepreneurial opportunities are constantly searching for information online, interacting with people, or reading related newspapers, magazines and books.

Association and connection (Tang et al., 2012) After gathering information, the person communicates creatively and 
consciously through the information obtained. Communication between different information leads to new options and unique communication.

Evaluation and judgement (Tang et al., 2012) People who are aware of entrepreneurial opportunities are well able to make meaningful connections between the information gathered.

The Power of Identifying Good Opportunities for the Those who are vigilant about entrepreneurial opportunities are well Bad (Tang et al., 2012) able to evaluate existing information and to distinguish profitable opportunities from non-profit opportunities.

The Power of Choosing Good Opportunities (Tang et Those who are vigilant about entrepreneurial opportunities are well al., 2012) positioned to evaluate the information available and to select profitable opportunities.

To address the previously neglected intrinsic aspect of alertness, theories from psychology and cognitive science are needed. There exist several theories in psychological sciences related to the intrinsic and metacognitive mechanisms of individuals, including mindfulness theory, metacognitive awareness theory, self-regulation theory and others. Among all these theories, mindfulness theory has been chosen in this article to address the lack of an intrinsic aspect of alertness in the entrepreneurial context.

\subsection{Mindfulness Factors}

There are two approaches toward mindfulness theory: the Eastern approach and the Western approach. The Eastern view of mindfulness is embedded in Buddhist philosophy. In Theravada Buddhism mindfulness is associated with two different meanings: a) to remember and b) to develop a lucid awareness. According to the first view, mindfulness is related to memory and so mindfulness enhances one's ability to remember past experiences. In the second view, mindfulness is related to what is happening in the present moment (Khoury et al., 2017). Within Buddhist thought a key reason for practicing mindfulness is long-term spiritual development and reduction of suffering that comes from attachment and grasping, rather than just symptomatic relief of stress.

Ellen Langer (1992) is a leading theorist for the Western view of mindfulness. According to her, mindfulness is considered as comprising (a) openness to novelty, (b) alertness to distinctions, (c) sensitivity to different contexts, (d) implicit, if not explicit, awareness of multiple perspectives, and (e) orientation in the present (Langer 1992). In this research, Langer's theory of mindfulness (1992) has been applied.

To classify the mindfulness factors that can affect entrepreneurial alertness, we performed a comprehensive review of mindfulness theory and the scales that exist for measuring mindfulness, both in Eastern and Western approaches. There exist several different tools to measure different aspects of mindfulness. We did a thorough investigation of mindfulness operationalization, which clarified which aspects of mindfulness needs to be taken into consideration for this study. Table 3 is a summary of the existing tools used to measure alertness.

Table 3. Mindfulness Operationalization

\section{Tool}

Mindfulness Attention Awareness Scale (MAAS)

Kentucky Inventory of Mindfulness Scales (KIMS)

The Toronto Mindfulness Scale (TMS)

Cognitive and Affective Mindfulness Scale Revised

(CAMS-R)

Five Factors Mindfulness Questionnaire (FFMQ)

\section{Aspects Being Measured} attentional aspect of mindfulness is measured observe, describe, act with awareness, non-reactive stance measures mindfulness as a state not as a trait attention, present focus, awareness, acceptance

non-reactivity to inner experience, observing/noticing/attending to sensations/perceptions/thoughts/feelings, acting with awareness/automatic pilot/concentration not-distraction, describing/labeling with words, non-judging of experience

Developmental Mindfulness Survey (DMS)

Freiburg Mindfulness Inventory (FMI)

Philadelphia Mindfulness Scale (PHLMS) awareness of the present, non-judgment stance present moment awareness, non-judgemental attitude awareness, acceptance

Southampton Mindfulness Scale (SMQ) present moment awareness, acceptance attitude

Langer Mindfulness/Mindlessness Scale curiosity, creativity, openness to novelty, awareness of multiple perspectives, sensitivity to context

From this summary, all the aspects of mindfulness and their measuring scales were reviewed and a list of factors were chosen as shown in Table 4. 
Table 4. Mindfulness Factors and Operational Definitions

\begin{tabular}{|c|c|}
\hline Factor & Operational Definition \\
\hline on-purpose attention & $\begin{array}{l}\text { On-purpose attention is one of the main elements of mindfulness. Conscious attention helps you } \\
\text { control and direct your attention every moment. Intentional orientation of attention enhances } \\
\text { awareness, transparency and clarity of reality which is taken into consideration. }\end{array}$ \\
\hline $\begin{array}{l}\text { present moment } \\
\text { awareness }\end{array}$ & $\begin{array}{l}\text { When you are aware of the present moment, you see the reality in all its internal and external aspects } \\
\text { and avoid interpretations from old beliefs or illusions of the future. }\end{array}$ \\
\hline non-judgemental & Being non-judgmental is defined as neither blaming nor evaluating the circumstances. \\
\hline openness to novelty & Openness to novelty is about being open-minded to trying something new or unique. \\
\hline sensitivity to context & $\begin{array}{l}\text { Sensitivity to context is defined as "how well a person can regulate their emotional responses to } \\
\text { include the environment they are in." }\end{array}$ \\
\hline non-reaction & $\begin{array}{l}\text { Non-reaction is making a conscious choice not to join an argument, or follow non-productive } \\
\text { thinking. }\end{array}$ \\
\hline self-regulation & $\begin{array}{l}\text { Self-regulation involves controlling one's behavior, emotions, and thoughts in the pursuit of } \\
\text { long-term goals. }\end{array}$ \\
\hline letting go & $\begin{array}{l}\text { Letting go is defined as a release: to liberate, disengage, or set free. It is a conscious choice; a mental } \\
\text { act that requires free will and effort. }\end{array}$ \\
\hline novelty seeking & Novelty seeking is defined as the degree to which an individual is receptive to new ideas. \\
\hline $\begin{array}{l}\text { awareness of multiple } \\
\text { perspectives }\end{array}$ & $\begin{array}{l}\text { Ability to review existing situations from different perspectives. This feature of the conscious person } \\
\text { refers to the ability during which the individual is able to examine the situation from the perspective } \\
\text { of different individuals. }\end{array}$ \\
\hline acceptance & $\begin{array}{l}\text { Acceptance is defined as a person's assent to the reality of a situation, recognizing a process or } \\
\text { condition (often a negative or uncomfortable situation) without attempting to change or protest. }\end{array}$ \\
\hline patience & $\begin{array}{l}\text { Patience is defined as the quality of being patient, as the bearing of provocation, misfortune, or pain, } \\
\text { without complaint, loss of temper, irritation or the like, an ability or willingness to suppress } \\
\text { restlessness or annoyance when confronted with delay. }\end{array}$ \\
\hline trust in God & $\begin{array}{l}\text { To trust in God means more than believing in who he is and what he says; the word here for trust can } \\
\text { also mean "to have confidence in." Having confidence in something means having an assurance that } \\
\text { leads to action. }\end{array}$ \\
\hline trust & $\begin{array}{l}\text { Trust is defined as "assured reliance on the character, ability, strength, or truth of someone or } \\
\text { something." }\end{array}$ \\
\hline meditation & $\begin{array}{l}\text { Meditation is defined as the control of fluctuations of the mind that aim to still the fluctuations } \\
\text { (patterning) of the mind. When the fluctuations of the mind are controlled, the meditator achieves } \\
\text { concentration. }\end{array}$ \\
\hline reflection & $\begin{array}{l}\text { Reflection is defined as "meditation or serious thought about one's character, actions, and motives." } \\
\text { It's about taking a step back and reflecting on your life, behavior and beliefs. }\end{array}$ \\
\hline
\end{tabular}

\section{Research Methodology}

In this research, in order to create a graphical representation of complex interaction between the specific elements of alertness and mindfulness, Interpretive Structural Modelling (ISM) has been used. ISM is used for exploring and theorizing relationships within complex issues (Khan, Ghazali, Abdullah, \& Isha, 2017). The main objective of this study is to explore the factors affecting entrepreneurs' alertness to opportunities and establishing a relationship among those factors. In the following section, the ISM process used in this research is explained. Based on the literature review that we did on mindfulness and alertness, we generated constructs for a model of the relationship between alertness and mindfulness. This study investigated the factors that appear to have the greatest influence on the entrepreneurs' alertness and opportunity recognition behaviour, and includes not only the factors identified by prevailing studies but also the additional factors generated through ISM sessions with experts and technological entrepreneurs. Twenty-six factors of the present study are suggested by prevailing theories that include: mindfulness theory suggested by Ellen Langer, Eastern approach toward mindfulness, Islamic spirituality, cognitive entrepreneurial alertness theory presented by Valliere (2013) and another entrepreneurial alertness theory presented by Tang et al. (2012). There are some additional factors suggested by academics and entrepreneurs, such as feeling the need, self-confidence, and hope. The present study considers a broad list of twenty-nine factors, of which 26 are suggested by the theory and three are additional contextual factors suggested by academics and entrepreneurs.

Warfield (1994) has classified several types of ISM modelling types or approaches, which are shown in Table 5. As the aim of this research is to explore the interrelation between mindfulness and entrepreneurial alertness factors, the intent structure is the best approach to be used because we want to understand the mutual influence between the elements of the model. 
Table 5. Types of ISM

\begin{tabular}{llll}
\hline Type of structure & Element class & Relation type & Examples \\
\hline Intent & $\begin{array}{l}\text { Interrelation between objectives, } \\
\text { goals and intentions }\end{array}$ & Influence & "would help to achieve", "supports" \\
\hline Priority & $\begin{array}{l}\text { Rank a number of items in order of } \\
\text { priority }\end{array}$ & Comparative & $\begin{array}{l}\text { "is of equal or higher priority", "is equal or } \\
\text { higher value than", "is more important than" }\end{array}$ \\
\hline $\begin{array}{l}\text { Attribute } \\
\text { enhancement }\end{array}$ & $\begin{array}{l}\text { interrelations between a set of } \\
\text { factors, problems or opportunities }\end{array}$ & influence & "strongly contributes to" \\
$\begin{array}{l}\text { Solution sequence or } \\
\text { process }\end{array}$ & Unknown variables & $\begin{array}{l}\text { Influence, } \\
\text { temporal }\end{array}$ & $\begin{array}{l}\text { "is a function of", "should be computed } \\
\text { before" }\end{array}$ \\
\hline Complementary & Any & Any & "is a complement of" \\
\hline
\end{tabular}

The influencing factors of entrepreneurial alertness have been explained from different perspectives and levels. In this research, we did a comprehensive literature review and found 29 factors that influence entrepreneurial alertness from cognitive and spiritual point of view. In the next step, we had an expert panel of 10 Iranian technological entrepreneurs to identify these factors. The panel members were familiar with mindfulness and spirituality and had experience with technological entrepreneurship. First, the practical definition of the 29 factors related to entrepreneurial alertness and mindfulness were explained to panel members. Then we asked the 10 entrepreneurs to evaluate the impact of all the 29 factors on entrepreneurial alertness. They were also asked to suggest any other factor that had not been mentioned in the literature. The results showed that more than eight entrepreneurs had an agreement on fourteen factors. In addition, two more factors i.e. self-confidence and hope, were added to the factors and more than two thirds of experts had agreement on it. After discussions between the experts and entrepreneurs, 13 contentious factors were removed and three new factors suggested and added. Finally we reached consensus on 16 factors. We removed the disputed factors because entrepreneurs needed to focus on the factors that were commonly accepted to be helpful on entrepreneurial alertness and opportunity recognition process. In the third step, after identification of 16 factors, entrepreneurs discussed the relationship between the influencing factors. They were asked to do a pair-wise comparison of the remaining 16 factors. The factors were signed $i$, where $\mathrm{i}=1,2, \ldots, 16$, as shown in Table 6 . Four types were assigned for judging the relationship between the factors $i$ and $j$, and entrepreneurs were asked to select one of the four types:

- Type V: When factor $i$ directly affects factor $j$

- Type A: When factor $j$ directly affects factor $i$

- Type X: When factors $i$ and $j$ had a reciprocal effect

- Type O: When factors $i$ and $j$ were unrelated.

It appeared that the entrepreneurs could easily make a consistent judgement on the pair-wise relationship of the 16 factors. The final results of the pair-wise comparison is illustrated in Table 6.

Table 6. Structural Self-Interaction Matrix (SSIM)

\begin{tabular}{|c|c|c|c|c|c|c|c|c|c|c|c|c|c|c|c|c|}
\hline & 1 & 2 & 3 & 4 & 5 & 6 & 7 & 8 & 9 & 10 & 11 & 12 & 13 & 14 & 15 & 16 \\
\hline 1- Scanning \& Search & & $\mathrm{X}$ & A & $\mathrm{O}$ & $\mathrm{X}$ & $\mathrm{O}$ & $\mathrm{A}$ & $\mathrm{X}$ & $\mathrm{A}$ & $\mathrm{V}$ & A & $\mathrm{O}$ & A & A & $\mathrm{O}$ & $\mathrm{V}$ \\
\hline 2- Novelty Seeking & & & A & $\mathrm{O}$ & $\mathrm{X}$ & $\mathrm{O}$ & $\mathrm{A}$ & $\mathrm{X}$ & A & $\mathrm{V}$ & A & $\mathrm{O}$ & A & A & $\mathrm{O}$ & $\mathrm{V}$ \\
\hline 3- Deliberate Search for Opportunities & & & & $\mathrm{A}$ & $\mathrm{V}$ & $\mathrm{V}$ & $\mathrm{X}$ & $\mathrm{V}$ & $\mathrm{O}$ & $\mathrm{V}$ & $\mathrm{O}$ & $\mathrm{O}$ & $\mathrm{V}$ & A & $\mathrm{O}$ & $\mathrm{V}$ \\
\hline 4- Acceptance & & & & & $\mathrm{O}$ & A & A & $\mathrm{O}$ & $\mathrm{V}$ & $\mathrm{O}$ & $\mathrm{O}$ & $\mathrm{O}$ & $\mathrm{O}$ & A & $\mathrm{O}$ & $\mathrm{V}$ \\
\hline 5- Sensitivity to Context & & & & & & $\mathrm{O}$ & $\mathrm{A}$ & $\mathrm{X}$ & $\mathrm{A}$ & $\mathrm{V}$ & A & $\mathrm{O}$ & A & A & $\mathrm{O}$ & $\mathrm{V}$ \\
\hline 6- Openness to Novelty & & & & & & & $\mathrm{A}$ & $\mathrm{O}$ & $\mathrm{A}$ & $\mathrm{V}$ & $\mathrm{O}$ & $\mathrm{O}$ & $\mathrm{O}$ & $\mathrm{A}$ & $\mathrm{O}$ & $\mathrm{V}$ \\
\hline 7- Association and Connection & & & & & & & & $\mathrm{V}$ & $\mathrm{O}$ & $\mathrm{V}$ & $\mathrm{O}$ & $\mathrm{O}$ & $\mathrm{V}$ & A & $\mathrm{O}$ & $\mathrm{V}$ \\
\hline 8- Deliberate Attention & & & & & & & & & $\mathrm{A}$ & $\mathrm{V}$ & A & $\mathrm{O}$ & A & $\mathrm{A}$ & $\mathrm{O}$ & $\mathrm{V}$ \\
\hline 9- Schematic Association & & & & & & & & & & $\mathrm{V}$ & $\mathrm{O}$ & $\mathrm{O}$ & $\mathrm{V}$ & A & $\mathrm{O}$ & $\mathrm{V}$ \\
\hline 10- Feeling the Need & & & & & & & & & & & A & $\mathrm{O}$ & $\mathrm{A}$ & A & $\mathrm{O}$ & $\mathrm{V}$ \\
\hline 11- Evaluation \& Judgment & & & & & & & & & & & & $\mathrm{O}$ & $\mathrm{V}$ & A & $\mathrm{O}$ & $\mathrm{V}$ \\
\hline 12- Hope & & & & & & & & & & & & & $\mathrm{O}$ & $\mathrm{O}$ & $\mathrm{V}$ & $\mathrm{V}$ \\
\hline 13- Awareness of Multiple Perspectives & & & & & & & & & & & & & & A & $\mathrm{O}$ & $\mathrm{V}$ \\
\hline 14-Looking for Underutilized resources & & & & & & & & & & & & & & & $\mathrm{O}$ & $\mathrm{V}$ \\
\hline 15-Self-Confidence & & & & & & & & & & & & & & & & $\mathrm{O}$ \\
\hline 16- Non-judgment & & & & & & & & & & & & & & & & \\
\hline
\end{tabular}

After the SSIM was made, it was transformed into a reachability matrix by changing the information in each entry of SSIM into 1s and 0s. The substitution of 1s and 0s were made per the following rules:

1. If $(i, j)$ entry in the SSIM is V, then $(i, j)$ entry in the reachability matrix becomes 1 and the $(j, i)$ entry becomes 0 . 
2. If $(i, j)$ entry in the SSIM is A, then $(i, j)$ entry in the reachability matrix becomes 0 and the $(j, i)$ entry becomes 1 .

3. If $(i, j)$ entry in the SSIM is X, then $(i, j)$ entry in the reachability matrix becomes 1 and the $(j, i)$ entry also becomes 1 .

4. If $(i, j)$ entry in the SSIM is $\mathrm{O}$, then $(i, j)$ entry in the reachability matrix becomes 0 and the $(j, i)$ entry also becomes 0 .

The resulting reachability matrix is shown in Table 7. The values shown in the Driving column of each factor illustrates its overall influence or "power" over the other factors. The value in the Dependence row of each factor signifies the degree to which it is influenced by other factors. The proposed model was developed as a graphical representation of these transitive reachability results. The proposed model of the study is presented in Figure 1.

Table 7. Reachable Matrix of the Factors

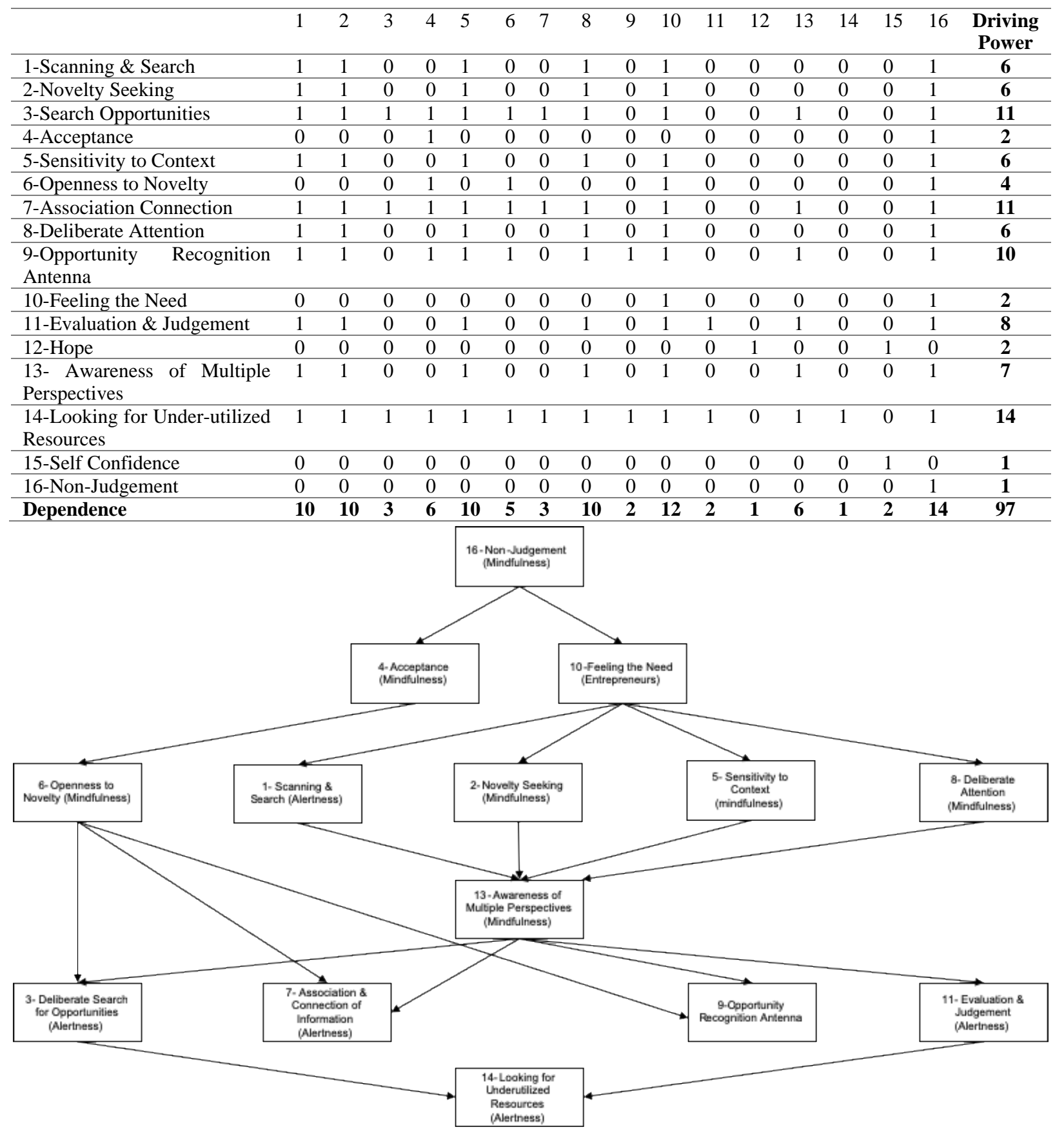

Figure 1. Multilevel Structure Hierarchy of the Factors 


\section{Results and Discussion}

As it is shown in the model, all the factors derived from the EA theories are connected with entrepreneurial alertness. However, two of the factors that were suggested by entrepreneurs were found to have no connection with entrepreneurial alertness. The other factor, feeling the need, which was suggested by entrepreneurs, emerged as the starting point of the model and affects entrepreneurs' propensity for opportunity recognition. This implies that the entrepreneurs in this study are more into necessity-based opportunities, which is very common in developing countries such as Iran. Entrepreneurs didn't see a big difference between the cognition and behaviours related to entrepreneurial alertness. However, the hierarchy of the factors in the model prove the driving effect of mindfulness on entrepreneurial alertness.

This study proposes a hierarchical model of factors affecting entrepreneurial alertness, which were recognized through a comprehensive literature review. We used the expert method based on Interpretive Structure Modelling (ISM) method of system dynamics. There exist extensive number of research that have explored the factors affecting entrepreneurial alertness in different contexts and levels including individual, firm and environmental level. We presented and intuitive ISM (Figure 1) for researchers which extends and integrates the prior research. According to the results, as key factors, being mindful to inner thoughts and emotions may have direct effect on entrepreneurial alertness. In fact, alertness and mindfulness are so close that, some experts have struggled to differentiate these two (e.g., Baron, 2006). The results of this study may provide a new perspective to researchers and practitioners of entrepreneurship. Researchers now have a clue to study the comprehensive function of mindfulness and emotion regulation on entrepreneurial alertness. In addition, the existing research dimensions and framework is integrated in this study which benefits further explorations of entrepreneurial alertness theory. A great opportunity is also provided for empirical study of entrepreneurial alertness and mindfulness.

Practitioners on the other hand, can benefit from this research findings which has potential implications for entrepreneurs and organizations. This paper has a clue for entrepreneurs to improve their ability to be more alert in recognizing entrepreneurial opportunities. However, it has its own limitations. The model presented here, is based on the ideas of a small number of entrepreneurs in Iran and it is not empirically tested. In addition, the entrepreneurs in this study are from Iran and the results might be different in different contexts. However, this doesn't negate that the entrepreneur's alertness and mindfulness deserve high attention due to their potential effect on the entrepreneurial opportunity recognition process. Entrepreneurs should maintain a high level of mindfulness and regulate their emotions to facilitate the benefits of entrepreneurial alertness.

\section{References}

Alvarez, S. A., \& Barney, J. B. (2007). Discovery and creation: Alternative theories of entrepreneurial action. Strategic Entrepreneurship Journal, 1(1-2), 11-26. https://doi.org/10.1002/sej.4

Ardichvili, A., Cardozo, R., \& Ray, S. (2003). A theory of entrepreneurial opportunity identification and development. Journal of Business Venturing, 18(1), 105-123. https://doi.org/10.1016/S0883-9026 (01)00068-4

Baron, R. A. (2004). The cognitive perspective: A valuable tool for answering entrepreneurship's basic "why" questions. Journal of Business Venturing, 19(2), 221-239. https://doi.org/10.1016/S0883-9026(03)00008-9

Baron, R. A. (2006). Opportunity recognition as pattern recognition: how entrepreneurs "connect the dots" to identify new business opportunities. Academy of Management Perspectives, 20(1), 104-119. https://doi.org/10.5465/amp.2006.19873412

Craig, J. B., \& Johnson, D. (2006). Establishing individual differences related to opportunity alertness and innovation dependent on academic - career training. Journal of Management Development, 25(1), 28-39. https://doi.org/10.1108/02621710610637945

Gaglio, C. M., \& Katz, J. A. (2001). The psychological basis of opportunity identification: entrepreneurial alertness. Small Business Economics, 16(2), 95-111. https://doi.org/10.1023/A:1011132102464

Ghasemi, B., \& Rowshan, A. (2016). Early warning: The role of market on entrepreneurial alertness. Journal of Intelligence Studies in Business, 6(2), 34-42. https://doi.org/10.37380/jisib.v6i2.171

Indrawati, N. K., Salim, U., Djumahir, \& Djawahir, A. H. (2015). The mediating role of entrepreneurial alertness in relationship between environmental dimensions and entrepreneurial commitment: Entrepreneurial self-efficacy as moderating variables. International Journal of Entrepreneurship and Small Business, 26(4), 467-489. https://doi.org/10.1504/IJESB.2015.072761

Kabat-Zinn, J. (1990). Full catastrophe living. New York: Delta Publishing. 
Khan, N. H. A. L., Ghazali, Z., Abdullah, M. R. T. L., \& Isha, A. S. N. (2017). Rationale and application of Interpretive Structural Modeling (ISM) in Safety Management Research. Global Business and Management Research: An International Journal, 9(1), 505-515.

Khoury, B. A. A., Knäuper, B. C., Pagnini, F. B. D., Trent, N. B., Chiesa, A. E. F., \& Carrière, K. C. (2017). Embodied Mindfulness. Mindfulness, 8(5), 1160-1171. https://doi.org/10.1007/s12671-017-0700-7

Kirzner, I. M. (1973). Competition and Entrepreneurship. University of Chicago Press: Chicago.

Kirzner, I. M. (1979). Perception, opportunity and profit: Studies in the Theory of Entrepreneurship. The University of Chicago Press: Chicago.

Kirzner, I. M. (2009). The alert and creative entrepreneur: a clarification. Small Business Economics, 32(2), 145-152. https://doi.org/10.1007/s11187-008-9153-7

Langer, E. J. (1992). Matters of mind: Mindfulness/mindlessness in perspective. Consciousness and cognition, l(3), 289-305. https://doi.org/10.1016/1053-8100(92)90066-J

Ma, R., \& Huang, Y. C. (2016). Opportunity - based strategic orientation, knowledge acquisition, and entrepreneurial alertness: The perspective of the global sourcing suppliers in China. Journal of Small Business Management, 54(3), 953-972. https://doi.org/10.1111/jsbm.12222

Nikraftar, T., \& Hosseini, E. (2016). Factors affecting entrepreneurial opportunities recognition in tourism small and medium sized enterprises. Tourism Review, 71(1), 6-17. https://doi.org/10.1108/TR-09-2015-0042

Obschonka, M., Hakkarainen, K., Lonka, K., \& Salmela-Aro, K. (2017). Entrepreneurship as a twenty-first century skill: entrepreneurial alertness and intention in the transition to adulthood. Small Business Economics, 48(3), 487-501. https://doi.org/10.1007/s11187-016-9798-6

Sarasvathy, S. D., Dew, N., Velamuri, S. R., \& Venkataraman, S. (2003). Three views of entrepreneurial opportunity. In Handbook of Entrepreneurship Research. USA: Springer.

Schøtt, T. (2017). Immigrant and indigenous youth in Europe: Entrepreneurial intention building on human, financial and social capital. International Journal of Entrepreneurship and Small Business, 30(3), 374-394. https://doi.org/10.1504/IJESB.2017.081981

Skarbek, D. (2009). Alertness, local knowledge, and Johnny Appleseed. The Review of Austrian Economics, 22(4), 415-424. https://doi.org/10.1007/s11138-008-0066-0

Sturm, W., \& Willmes, K. (2001). On the functional neuroanatomy of intrinsic and phasic alertness. Neuroimage, 14(1), S76-S84. https://doi.org/10.1006/nimg.2001.0839

Sturm, W., Longoni, F., Fimm, B., Dietrich, T., Weis, S., Kemna, S., \& Willmes, K. (2004). Network for auditory intrinsic alertness: a PET study. Neuropsychologia, 42(5), 563-568. https://doi.org/10.1016/j.neuropsychologia.2003.11.004

Sturm, W., Simone, A. d., Krause, B. J., Specht, K., Hesselmann, V., Radermacher, I., \& Willmes, K. (1999). Functional anatomy of intrinsic alertness: evidencefor a fronto-parietal-thalamic-brainstem network in the right hemisphere. Neuropsychologia, 37(7), 797-805. https://doi.org/10.1016/S0028-3932(98)00141-9

Syed, I., \& Mueller, B. (2015). Follow your passion: How entrepreneurial passion motivates alertness to opportunities? Frontiers of Entrepreneurship Research, 35(5), 21-32. https://doi.org/10.5465/ambpp.2015.161

Tang, J. (2008). Environmental munificence for entrepreneurs: Entrepreneurial alertness and commitment. International Journal of Entrepreneurial Behavior \& Research, 14(3), 128-151. https://doi.org/10.1108/13552550810874664

Tang, J. (2009). Exploring the constitution of entrepreneurial alertness: The regulatory focus view. Journal of Small Business \& Entrepreneurship, 22(3), 221-238. https://doi.org/10.1080/08276331.2009.10593452

Tang, J., Kacmar, K. M., \& Busenitz, L. (2009). A social cognition view of alertness in the discovery process of entrepreneurial opportunities. Academy of Management Proceedings, 2009(1), 1-6. https://doi.org/10.5465/ambpp.2009.44244568

Tang, J., Kacmar, K. M., \& Busenitz, L. (2012). Entrepreneurial alertness in the pursuit of new opportunities. Journal of Business Venturing, 27(1), 77-94. https://doi.org/10.1016/j.jbusvent.2010.07.001

Valliere, D. (2013). Towards a schematic theory of entrepreneurial alertness. Journal of Business Venturing, 28(3), 430-432. https://doi.org/10.1016/j.jbusvent.2011.08.004 
Warfield, J. N. (1994). Science of generic design: Managing complexity through systems design. Iowa State Press.

Yu, F. L. T. (2001). Entrepreneurial Alertness and Discovery. The Review of Austrian Economics, 14(1), 47-63. https://doi.org/10.1023/A:1007855505727

\section{Copyrights}

Copyright for this article is retained by the author(s), with first publication rights granted to the journal.

This is an open-access article distributed under the terms and conditions of the Creative Commons Attribution license (http://creativecommons.org/licenses/by/4.0/). 